\title{
Téoros
}

Revue de recherche en tourisme

\section{Le carnaval de Rio : une fête qui a son prix}

\section{Maria Geralda de Almeida et Normand Cazelais}

Volume 5, numéro 2, juillet 1986

Tourisme, fêtes et événements

URI : https://id.erudit.org/iderudit/1080572ar

DOI : https://doi.org/10.7202/1080572ar

Aller au sommaire du numéro

Éditeur(s)

Université du Québec à Montréal

ISSN

0712-8657 (imprimé)

1923-2705 (numérique)

Découvrir la revue

Citer cet article

de Almeida, M. G. \& Cazelais, N. (1986). Le carnaval de Rio : une fête qui a son prix. Téoros, 5(2), 11-40. https://doi.org/10.7202/1080572ar d'utilisation que vous pouvez consulter en ligne.

https://apropos.erudit.org/fr/usagers/politique-dutilisation/ 


\title{
Le carnaval de Rio: une fête qui a son prix
}

\author{
par Maria Geralda de Almeida et Normand Cazelais *
}

Aussi étonnant qu'il puisse paraittre, il n'est guère aisé d'obtenir des données qui permettraient de situer, dans une perspective évolutive, la fréquentation et les retombées économiques de cet événement mondialement connu -sinon couru- qu"est devenu le Carnaval de Rio. Et ce, méme en s'adressant à Riotur, le puissant office du tourisme de Rio de Janeiro..

Pourtant, le Carnaval de Rio pourrait à juste titre être évoqué comme le prototype de la grande fête populaire devenue événement touristique majeur. Et l'on aurait pu croire pour cette raison qu'il aurait été analysé sous toutes les coutures et que les sources d'information le concernant auraient été multiples et variées. Mais là n'est pas le moindre paradoxe.

\section{De l'entrudo au carnaval}

Faisons un peu d'histoire. Si celui de Rio est le plus connu, le carnaval constitue la fête la plus populaire à travers tout le Brésil. Comme il a lieu au cours des 40 jours qui précèdent le carème, il n'a pas de date fixe et trouve son paroxysme dans les jours et les nuits qui viennent avant le mercredi des Cendres. premier jour du carểne. Alors, de Rio jusqu'aux petits villages, c'est le règne de la samba, des danseurs, de l'alcool et d'une certaine joie de vivre. On dit au Brésil que l'ambiance du carnaval est celle que le diable veut et que Dieu aime!..

Au 18 e siècle, lorsque le Brésil était encore une colonie portugaise. le dimanche annonçant la venue du carềme était également le début de $1^{\text {tentrudoll: }}$ : pendant ces journées. les gens se promenaient dans les rues en s'aspergeant les uns les autres d"eau parfumée, de limoès-de-cheiro (citrons) ou mème d'autres liquides moins agréables. Par les fenêtres et les balcons, les résidents et leurs invites arrosaient copieusement d'eau et de farine ceux et celles qui se risquaient dans les rues. Aprés quelques heures de ce genre de jeu. les gens allaient se

- Maria Geralda de Almeida est protesseure de gitogra. phie a l'Universite federale de Sergipe a Aracaju dans le Nordeste bresilien. Normand Cazelais est chroniqueur en tourisme et membre du comité de rédaction de Téoros

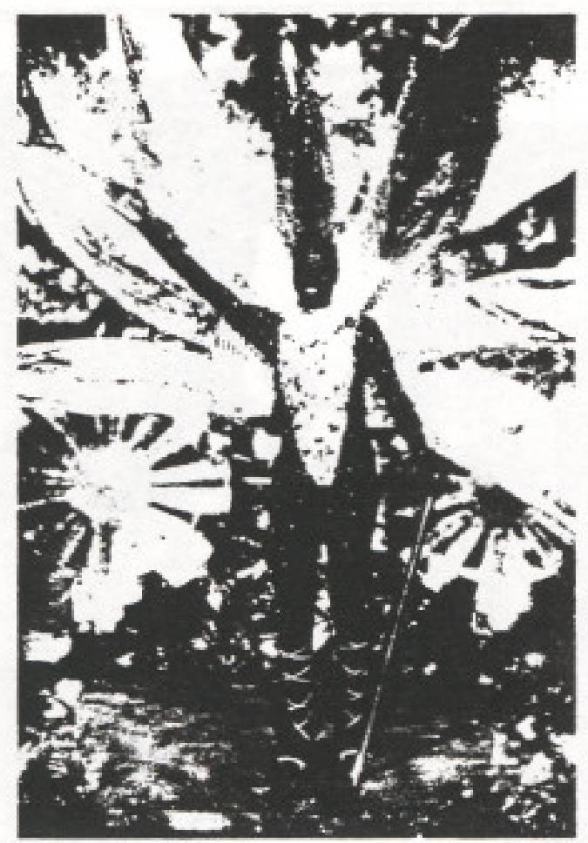

On dit au Brésil que l'ambiance du carnaval est celle que le diable veut at que Dieu aimel

baigner puis se restaurer d'un copieux repas.

Avec le temps. l'entrudo a beaucoup changé. La farine fut remplacés par une poudre rouge vif, le vermelhà, qui servait à colorer les chaussures. Les "échanges" devinrent moins amicaux et les bagarres se firent chaque fois plus nombreuses et violentes. De moins en moins de personnes sortaient de chez elles pour participer à l'entrudo, Aussi, vers 1880 , la police commençà-t=elle à interdire l'entrudo dans les rue des principales villes brésiliennes et à encourager par ailleurs le développement du carnaval, moins agressif que l'entrudo.

On commençait alors le carnaval le samedi, vers 20h30. A Salvador de Bahia, un quadrille dont l'air était adapté de certains extraits de l'opéra La Traviata (') ouvrait le bal; on y jouait également des valses, des polkas, des schottisehs. Vers 1890 est apparu le $Z \dot{Z}$ Pereira, bonhomme plein d'entrain qui jouait du tambour pour inviter tout le monde à faire le tour de la ville au rythme de la musique: des bandes de musiciens et de danseurs l'accompagnaient.

Jusque là, le carnaval était demeuré une fête familiale qui se célébrait à la maison. Avec l'interdiction de l'entrudo, les familles quittèrent peu à peu la quiétude des foyers pour s'aventurer vers des lieux publics, des salles de theătre ou de danse, pour s'aventurer dans la rue. Les commerçants, banquiers, grands propriétaires et autres membres de la bourgeoisie portaient toutefois des masques et même des déguisements afin de préserver leur anonymat. Mais la richesse et l'élaboration des masques et costumes illustraient amplement la prospérité de ces familles dont certaines importaient tissus et matériel des meilleures maisons françaises et anglaises. Des commerçants locaux les approvisionnaient - souvent en cachette -, pour préserver l'honorabilié et la bonne réputation de leurs cients qui $n$ "auraient pas dû, n'est-ce pas, s"intéresser à de telles futilités. Toujours est-il que ce type d"activités commerciales de luxe s'est considérablement développé avec les années et a influencé l'évolution du carnaval.

La participation de la bourgeoisie a, entre autres, entraine l'apparition des corsos, des chars allégoriques, et de leur défilé dans les rues. Les chroniques de l'époque rappellent, par exemple en 1884 à Salvador, la splendeur d'un corso au décor entièrement importé d'Europe et la richesse des costumes des garçons et filles. Les garçons, issus de la bourgeoisie, étaient particulièrement enthousiastes et la marche triomphale d'Aida de Verdi marquait toujours le début de leurs présentations camavalesques. Peu a peu sont apparus d'autres groupes de danse: les cordoés, les blocos, les ranchos, les escolas de samba.

Il faut d'autre part souligner que jusqu'en 1894 le carnaval stait une féte de blancs. mème à Bahia. Certes, les noirs fétaient mais c'étaient les blancs qui fréquentaient les lieux de divertissement et les bals, qui envahissaient les rues... En 1895 , les noirs nagós organiserent le premier afoxé. l'Embaixada Africana, en portant des véte-

(Suite a la page 40 ) 


\section{RIO}

|suite de la page 111

ments et bijoux venus d'Afrique. En fait, la première "école" de samba, si associée de nos jours à l'idée du carnaval brésilien, ne naquit qu'en 1928 dans le quartier d'Estacio à Rio' d'autres, a Penha, à Mengueira, à Salgueiro et Leblon, suivirent bientôt.

A l'origine, une école de samba était constituée de résidents de chaque quartier ou de chaque colline entourant la ville. Leur suc= cès fut tel qu'elles se répandirent très rapidement par tout le pays. Par sa beauté et par la gaieté qu'il dégage, le défilé des écoles de samba constitue maintenant le point culminant du carnaval et du camaval de Rio en particulier, un spectacle incroyablement animé et coloré. Tous les ans, les ecoles élisent leurs chorégraphes et décident du theme de leurs prestations, basé sur un épisode de l'histoire du Brésil ou de son folklore.

Ainsi, chaque école présentera pendant le carnaval des chars allégoriques, des orchestres entiers armés de batteries et d'instruments de percussion ainsi que des centaines sinon des milliers de participants vẻtus, pour beaucoup, de riches costumes. De riches costumes que, de toute évidence, ils ne peuvent pas se payer. On évalue en effet que le coût moyen d'un costume d'une école de samba est de $80 \$$ US, soit le double du salaire minimum mensuel.

Ces coûts montent d'ailleurs en spirale et ne sont pas près de s'arrêter, en raison notamment de la concurrence effrénée que se livrent les diverses écoles pour s'approprier les prix que donne la minicipalité de Rio à la meilleure chanson de samba, aux plus beaux costumes, au plus beau char allégorique, à la meilleure performance générale. Un million de dollars US seraient ainsi dépensés ces derniêres années en de tels préparatifs. Certaines écoles renommées peuvent profiter du support financier de commanditaires alors que d'autres acceptent dans leurs rangs -contre rémunération- des outsiders, des résidents de quartiers plus riches et plus huppés; il demeure que beaucoup de personnes s'endettent lourdement en prévision des jours de carnaval et connaissent un réveil douloureux au matin du mereredi des Cendres...

\section{Un événement de plus en plus "tourné" vers l'extérieur}

Cette concurrence n'est pas sur le point de s'éteindre car elle fait dorénavant partie du produit. D'où l'intérêt de la municipalité de l'attiser. L'an dernier, quelques 40000 touristes, venus des Etats-Unis, d'Europe. d'Argentine, auraient afflué vers Rio pour connaitre les joies de la "grande fiesta". Avec la dévaluation de la monnale brésilienne, cela voulait dire d'importants achats de vêtements, de souliers. d'objets d'artisans et d'autres produits locaux: 80 millions de dollars. US auraient ainsi été injectés dans l'économie de Rio, seulement au cours des dix derniers jours du Carnaval!

Pour ne pas ëtre en reste, une quinzaine de grandes écoles ont formé une association indépendante d'ecoles de samba afin de mieux profiter des retombes financieres de l'événement et aussi des redevances des compagnies de disques qui publient chaque année -à raison de 700000 exemplaires!les plus populaires chansons de carnaval. Le gouvernement de Rio a lui-mème financé et construit un gigantesque Sambadrome de 90000 places (dessiné par Oscar Niemeyer, l'architecte de Brasilia) au coût de 15 millions de dollars. Mais les prix des billets y sont chers ( 455 par jour en moyenne), beaucoup plus que la très grande majorité de cariocas (habitants de Rio) ne peuvent payer. Et, comme les touristes ne peuvent tout de meme pas acheter tous les billets chaque jour et qu'il y a conséquemment un grand nombre d"invendus, on parle de scandale..

Quoi qu*il en soit, le carnaval de Rio illustre bien le cas d'une fête issue des forces "internes" d'une collectivité, de son imaginaire lé plus intime, qui est devenue un événement touristique, donc tourné vers l'extérieur, vers les attentes de populations externes, et les "bénéfices" "qu'elles apportent. Même si cela doit se faire au détriment des premiers et principaux artisans de la fềte.

\section{Niote}

(1) Dansison classique ouvrage, Voyage pittoresque et historique au Brésil. J.B. Debret a fait une excel. lente analyse et description de l'enfrudo.
HARMONIE

|suite de la page 25 |

biliser périodiquement les plus hautes instances aux difficultés opérationnelles de ceux-ci afin d'éclairer et d'accélérer les prisés de décision. Enfin, une centralisation des informations et des données relatives à ces événements spécifiques devrait être effectuée en vue d'en arriver à fournir des. références aux futurs concepteurs et promoteurs.

Il est certain que des coûts et des délais sont reliés à ces recommandations. Il faut payer un prix lorsque l'on vise la qualité. La réputation et la crédibilité d'une région, d'une province ou d'un pays ne peuvent s'établir que dans la mesure où les activités qui l'identifient sont de qualité. $f$

\section{Pdiférences}

Cet article a ete tecrit a partir du travall L'importance des atapes de faisabilité dans la ratisation de Quá. bee 1534-1984 et de projets similaires realisé par Gilles. Delorme dans le cadre du "Séminaire d'intégration $I^{\prime \prime}$ de le maitrise en pestion de projet-UOAM. Les documents consultes pour réaliser ce travail sont:

- Analyse sur la capacité du site au niveas humain, Qufbec, 1534-1984.

- LAVALIN, Circulation-Transport 1984-Plan de traneport et elrculation Qutbec, ote 1984, 23 févier 1984.

- Comité Cudbec 1534-1954, Rapport d'étude sur I'dvónement Qud́bac 1534-1984, Aoủt 1979

- Croissance de l'́buenement Qutbec 84. Commis sion rogionale Jean-Talon, Deuxieme trimestre 1994

- capon belanger onllaipe, gagnon comptables agrets. Etude de to gestion adminis: trative et financibre - Québec, Decembre 1984.

- ROCHE Ltée Groupe consiil. Etude des retembees exconomiques des dvenements publies du 450 e anniversaire de l'arrivere de Jacques Cartier au Canade - Rapport d'btape no 1, Dossier 3943-1000, Juin 1904 .

- ROCHE Ltée Groupe conseil, Etude des ratombebes diconomiques das ovónaments publics du 450 e anniversaire de l'arrivete de Jecques. $C$ ar tier au Canada. Dossier 3943-1000. Mars 1985.

- P.A. Cloutier, Gestion par projet, Automne 1985.

- Direction de l'evaluation - Agence canadienne de desweloppament intemational, Guide máthodologi. que a l'intention des equipes de projets qui ont a getrer des dvaluations. Oetobre 1980.

- Yves GRANDMONT M.Sc.A., Ing., La planification et le contrble en contexte de projet. Univétsité du Quebec aै Trois-Rivieres.

- Le projer Oubbec 15.341984 - Analyse du from. bre de visiteurs prévus ot des retombés éco nomiques escomptées, Office du tourisme du Canada.

- Rapport du Comité sur la responsabilité sociale de l'entreprist. Chambre de commerce de Canada, Novembre 1982 